\title{
Numerical analysis and experimental testing of ultra-high performance fibre reinforced concrete keyed dry and epoxy joints in precast segmental bridge girders
}

\author{
Balamurugan A. Gopal ${ }^{1} \cdot$ Farzad Hejazi $^{1}$ (D) Milad Hafezolghorani ${ }^{2} \cdot$ Voo Yen Lei $^{3}$
}

Received: 2 February 2019 / Accepted: 4 October 2019 / Published online: 23 October 2019

(c) The Author(s) 2019

\begin{abstract}
Although ultra-high performance fiber reinforced concrete (UHPFRC) has been used recently as a sustainable construction technique for many precast segmental bridges (PSBs), no exhaustive numerical and experimental studies exist to assess the shear capacity and failure pattern of the joints in these bridges. Hence, to accurately investigate the shear behavior of the joints in UHPFRC precast segmental bridges, a numerical analysis model based on finite-element code was established in this study. Concrete damaged plasticity model was used to analyze the UHPFRC joint models by considering all the geometries, boundaries, interactions and constraints. In this paper, the numerical model was calibrated by two full-scale UHPFRC keyed dry and epoxy joints under confining pressure effect. The excellent agreement between the numerical results and experimental data demonstrated the reliability of the proposed numerical model. The validated numerical model was then utilized to investigate the parameters affecting shear behaviour of the joints in PSBs. For this purpose, 12 FE models were analyzed under different variable parameters namely, number of shear keys, confining stress, and types of joints (dry or epoxy). Furthermore, the numerical results were also compared with the five existing shear design provision models available in literature in terms of ultimate shear capacity.
\end{abstract}

Keywords Shear keys · UHPFRC · FE model · Dry and epoxy joints · Precast segmental bridge

\section{Introduction}

An extensive review of the literature identified more than 300 completed bridges (i.e. pedestrian and motorway bridges combined) constructed worldwide using UHPFRC in one or more components (Binard 2017; Voo et al. 2018). In

Farzad Hejazi

farzad@fhejazi.com

Balamurugan A. Gopal

gbala@jkr.gov.my

Milad Hafezolghorani

milad@dura.com.my

Voo Yen Lei

vooyenlei@dura.com.my

1 Department of Civil Engineering, University Putra Malaysia, Serdang, Malaysia

2 DURA Technology Sdn Bhd, Kuala Lumpur, Malaysia

3 School of Civil and Environmental Engineering, University of New South Wales, Sydney, Australia brief, UHPFRC is an ultra-high strength cementitious material that contains a high quantity of cement and silica fume, low quantity of water, incorporates large amounts of fibres and exhibits remarkable characteristics such as high fracture energy, low permeability, limited shrinkage and increased corrosion resistance (Buttignol et al. 2017; El-Tawil et al. 2018). Although UHPFRC precast segmental bridges (PSBs) have been widely used in many countries (Voo and Foster 2016; Hafezolghorani and Voo 2018; Chen et al. 2016), there is relatively scant information available on the shear behaviour and design of such bridges, especially related to the joints between the segments. One of the most used techniques in the PSBs is in their construction using dry keyed joints as the speed of erection and the lack of reliance on weather conditions make this technique more suitable than using epoxy joints (Issa and Abdalla 2007; $\mathrm{Bu}$ and $\mathrm{Wu}$ 2018). However, the shear load capacity of the joints in PSBs increases by applying epoxy layer across the segments joints (Shamass et al. 2016; Zhou et al. 2005). Rombach (2004), Shamass et al. (2015) and Han et al. (2017) investigated the behaviour of reinforced concrete (RC) multiple-keyed 
dry joints both numerically and experimentally. Zhou et al. (2005) performed a series of experimental tests and analysed the behaviour of RC single and three-keyed dry joints. A finite-element study investigated the shear strength of RC dry joints of concrete panels to be used in PSBs with external prestressing under combined shear and flexure (Turmo et al. 2006). Hu and Xie (2016) investigated and simulated the bending and twisting working conditions between the shear keys and segments where ultimately, some structural strengthen suggestions on RC shear keys were offered. Nowadays, use of unreinforced small epoxy keys distributed across the precast concrete segmental box girder bridges is a common practice among countries with cold weather. A numerical finite element model analysis using Abaqus program was performed to simulate the shear-off failure of unreinforced RC keyed epoxy joints (Shamass et al. 2016). In this study, damaged plasticity model was used to simulate the concrete material and epoxy layer was modelled as linear elastic material. Initial numerical investigations and experimental tests (Voo et al. 2014; Shin 2017; Jang et al. 2017) indicated that shear strength capacity of UHPFRC keyed dry joints increased with the increase in confining stress and with an increasing number of shear keys. Voo et al. (2014) conducted six-keyed dry joints under push-of setup up to failure and investigated the effects of number of shear keys and amount of confining pressure on the shear capacity on the full-scale specimens. They proposed a shear deign provision approach to estimate the ultimate shear capacity of these jonits, however more test data are needed to validate the accuracy of the proposed approach.

In most previous studies like those presented above, the existing numerical models and empirical formulas from different researchers and design standard codes for calculating the shear capacity of keyed dry and epoxy joints were only dedicated to RC precast segmental bridges [Eqs. (1)-(6)] which lead to different and uncertain values.

Kaneko et al. (1993) proposed shear design provision models to estimate ultimate shear capacity $\left(V_{\mathrm{u}}\right)$ of keyed dry joints with normal strength concrete (20 $\mathrm{MPa} \leq f_{\text {ck }} \leq 50 \mathrm{MPa}$ ) and high strength concrete $\left(50 \mathrm{MPa}<f_{\mathrm{ck}} \leq 90 \mathrm{MPa}\right)$ as follows:

$V_{\mathrm{u}}=A_{\mathrm{k}} \frac{f_{\mathrm{ck}}^{2 / 3}}{100}\left(7 \sigma_{\mathrm{n}}+33\right)+0.6 A_{\mathrm{sm}} \sigma_{\mathrm{n}}\left(f_{\mathrm{ck}} \leq 50 \mathrm{MPa}\right)$

$V_{\mathrm{u}}=A_{\mathrm{k}} \frac{\ln \left(1+\frac{f_{\mathrm{ck}}}{10}\right)}{100}\left(49 \sigma_{\mathrm{n}}+233\right)+0.6 A_{\mathrm{sm}} \sigma_{\mathrm{n}}\left(f_{\mathrm{ck}}>50 \mathrm{MPa}\right)$

where, $A_{\mathrm{k}}, f_{\mathrm{ck}}, \sigma_{\mathrm{n}}$ and $A_{\mathrm{sm}}$ are the area of all the shear keys at the failure plane, characteristic compressive cylinder strength of concrete, confining pressure applied across the joint and smooth area of the joint.

Spanish Standard ATEP (1996) recommends a formula which is reliant upon the sum area of the joint surface as given below:

$V_{\mathrm{u}}=A_{\mathrm{k}}\left(1.14 \sigma_{\mathrm{n}}+1.8 \sqrt{f_{\mathrm{ck}}}\right)+0.6 A_{\mathrm{sm}} \sigma_{\mathrm{n}}$

AASHTO (1999) suggested a formula to be included as part of the American design code, which separates the shear strength conveyed by the keys from the strength given by the smooth surfaces in contact as presented in Eq. (4).

$V_{\mathrm{u}}=A_{\mathrm{k}} \sqrt{f_{\mathrm{ck}}}\left(0.2048 \sigma_{\mathrm{n}}+0.9961\right)+0.6 A_{\mathrm{sm}} \sigma_{\mathrm{n}}$

Rombach and Specker (Rombach and Specker 2004) analysed the behaviour of multiple-keyed joints by an FE model and proposed the following formula:

$V_{\mathrm{u}}=0.14 A_{\mathrm{k}} f_{\mathrm{cm}}+0.65\left(A_{\mathrm{sm}}+A_{\mathrm{k}}\right) \sigma_{\mathrm{n}}$

where $f_{\mathrm{cm}}$ is mean value compressive cylinder strength of concrete.

Turmo et al. (2006) recommended a novel formula for inclusion in the Eurocode predicated on the AASHTO formula as:

$V_{\mathrm{u}}=A_{\mathrm{k}} \sqrt{f_{\mathrm{cd}}}\left(0.1863 \sigma_{\mathrm{n}}+0.9064\right)+0.45 A_{\mathrm{sm}} \sigma_{\mathrm{n}}$

where, $f_{\mathrm{cd}}=\alpha_{\mathrm{cc}} f_{\mathrm{ck}} / \gamma_{\mathrm{c}}$ is design compressive strength. $\alpha_{\mathrm{cc}}=1$ and $\gamma_{c}=1.5$ are long term effects coefficient and partial safety factor of concrete according to Eurocode 2 (BS 1992).

Hence, there is no numerical model, enough experiments, and practical code provisions to calculate the shear capacity of the UHPFRC dry and especially epoxy joints. To address this issue, this paper presents a numerical analysis model using Abaqus FE code to analyze full-scale UHPFRC joint models with different variable parameters (i.e. number of shear keys, confining stress, and types of joints). Furthermore, to validate the FE models, two full-scale UHPFRC keyed joint specimens were tested under direct shear test and the numerical and experimental results compared together.

\section{Proposed numerical model for UHPFRC shear joints}

In this study, FE computer program code Abaqus (2011) was used to simulate the 3D UHPFRC keyed joint models under increasing direct shear loading as illustrated in Fig. 1. A 3D mesh type "reduced-integration 8-noded linear brick, hourglass control" (C3D8R) with element size of $25 \mathrm{~mm}$ was chosen for male and female components of the shear joint models to ensure the compatibility of mesh topology [see 


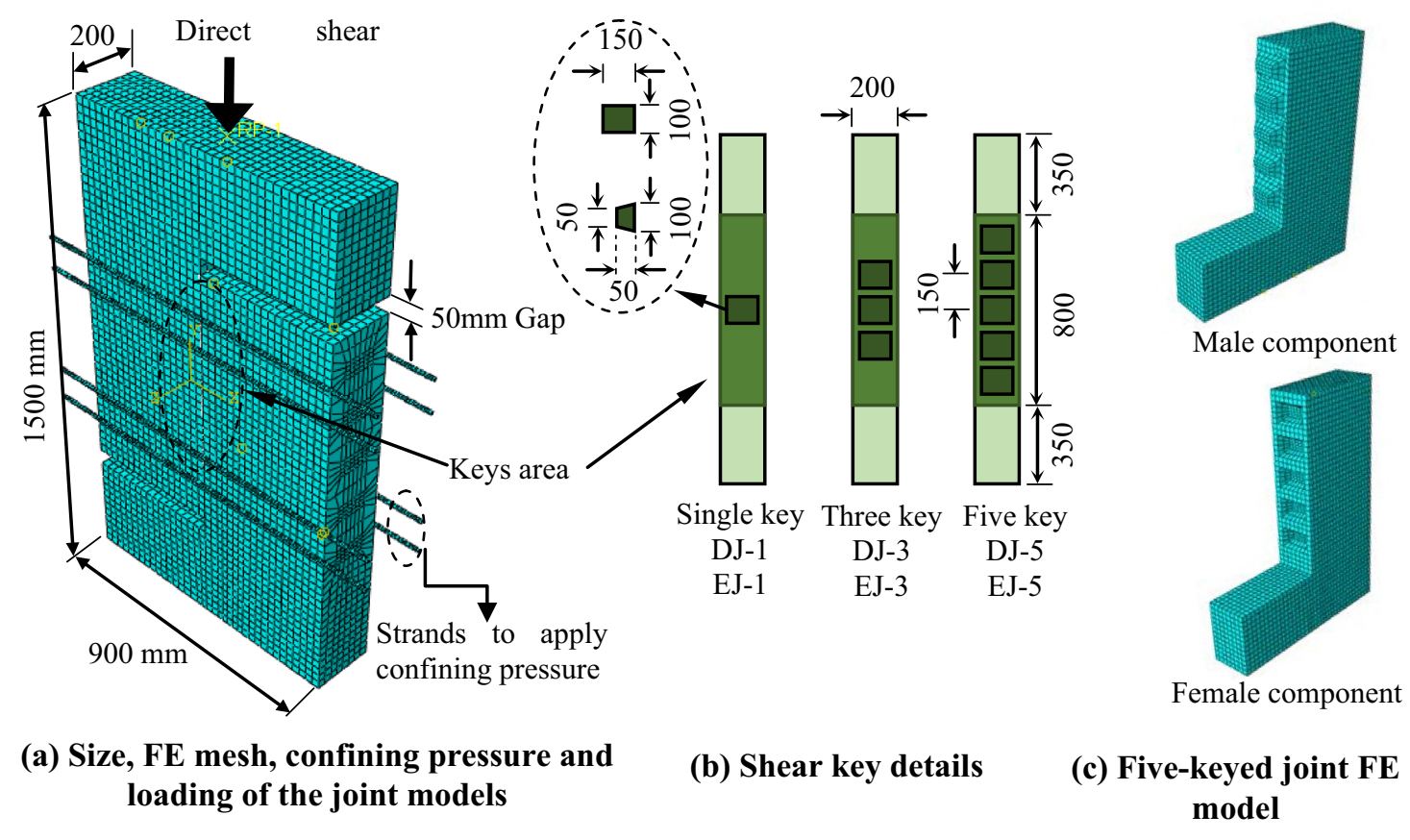

Fig. 1 Dimensions and details of the proposed FE keyed joints

Fig. 1a, c]. Prestressing strands were modelledas a 2-node linear 3D truss elements (T3D2) with mesh element size of $12 \mathrm{~mm}$ as shown in Fig. 1a. In Abaqus program code, there are three different constitutive models in order to simulate concrete material(i.e. concrete damaged plasticity (CDP), smeared crack (SC) and brittle model). In this study, the CDP model was chosen which is a suitable method to accurately simulate the inelastic behaviour of concrete in compression and tension (Hafezolghorani et al. 2017). In this study, the uniaxial compressive stress-strain relation, effective parameters called damages in compression and tension and initial parameters were chosen according to the previous studies in the literature (Shamass et al. 2015; Mansur and Ong 1991). In contact modeling, the interaction of the male to female models without epoxy was chosen as surface to surface with frictionless interaction property, while for the numerical models with epoxy, the effect of epoxy was considered through friction coefficient of 0.3 (Mihu et al. 2017). As shown in Fig. 1a, surface to surface interaction was selected for the contact between the prestressing strands and the UHPFRC male and female components and the effects of confining pressure were applied to the shear joint models using predefined field stress in X-direction (Sigma11).

\section{Parametric study and validation of the proposed numerical model}

In this study, a parametric study was performed to investigate the effects of various number of keys (single, three and five keys), type of joints (dry and epoxy) and amount of confining stress (10 MPa and $20 \mathrm{MPa}$ ) on the shear capacity of the full-scale keyed joint models as listed in Table 1 . In this table, the joint models were designated as $D$ or $E J X-Y$, where $D$ or $E$ are the models without or with epoxy across the joint, respectively, $X$ represents the number of shear keys and $Y$ indicates the average confining pressure applied to the joints through prestressing strands. For instance, joint model EJ5-20 is five-keyed epoxy joint with confining pressure level of $20 \mathrm{MPa}$. In general, a total of twelve UHPFRC full-scale FE shear keyed joint models were analysed by considering all the geometries, boundaries, interactions and constraints as shown in Fig. 1. In Table $1, A_{\mathrm{k}}$ and $A_{\mathrm{sm}}$ are total shear key area and smooth contact surface of the failure plane, respectively.

In the current research, in order to verify the proposed FE model, two full-scale UHPFRC five-keyed dry and epoxy joints subjected to confining pressure level of 20 $\mathrm{kN}$ (i.e. DJ5-20 and EJ5-20) were casted and tested under direct shear load as shown in Fig. 2.

The keyed joint specimens were cast through employing the male and female match-cast method. The first stage of the casting procedure of the UHPFRC shear keyed joint specimens started with the female components, then demoulded following $24 \mathrm{~h}$. The second stage consisted of casting the male components and during casting, initial curing was performed before standard heat curing. Within 30 min of casting, the exposed surface of the male and 
Table 1 Summary of the FE models

\begin{tabular}{lllllll}
\hline No. & Models & No. of keys & $\begin{array}{l}\text { Confining stress } \\
\sigma_{\mathrm{n}}(\mathrm{MPa})\end{array}$ & Type of joints & $A_{\mathrm{k}}\left(\mathrm{mm}^{2}\right)$ & $A_{\mathrm{sm}}\left(\mathrm{mm}^{2}\right)$ \\
\hline 1 & DJ1-10 & 1 & 10 & Dry & 15,000 & 145,000 \\
2 & EJ1-10 & 1 & 10 & Epoxy & 15,000 & 145,000 \\
3 & DJ1-20 & 1 & 20 & Dry & 15,000 & 145,000 \\
4 & EJ1-20 & 1 & 20 & Epoxy & 15,000 & 145,000 \\
5 & DJ3-10 & 3 & 10 & Dry & 45,000 & 115,000 \\
6 & EJ3-10 & 3 & 10 & Epoxy & 45,000 & 115,000 \\
7 & DJ3-20 & 3 & 20 & Dry & 45,000 & 115,000 \\
8 & EJ3-20 & 3 & 20 & Epoxy & 45,000 & 115,000 \\
9 & DJ5-10 & 5 & 10 & Dry & 75,000 & 85,000 \\
10 & EJ5-10 & 5 & 10 & Epoxy & 75,000 & 85,000 \\
11 & DJ5-20 & 5 & 20 & Dry & 75,000 & 85,000 \\
12 & EJ5-20 & 5 & 20 & Epoxy & 75,000 & 85,000 \\
\hline
\end{tabular}

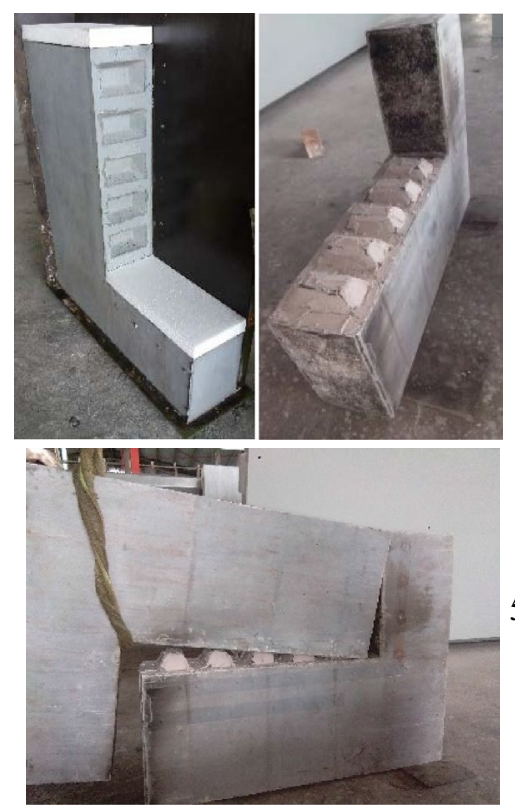

(a) Casting and preparation of the joint specimens

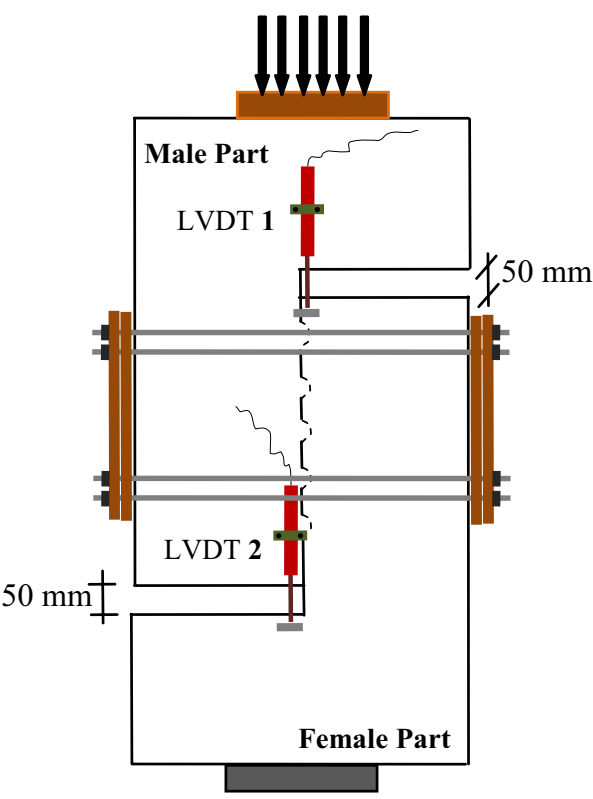

(b) Schematic view of the test setup

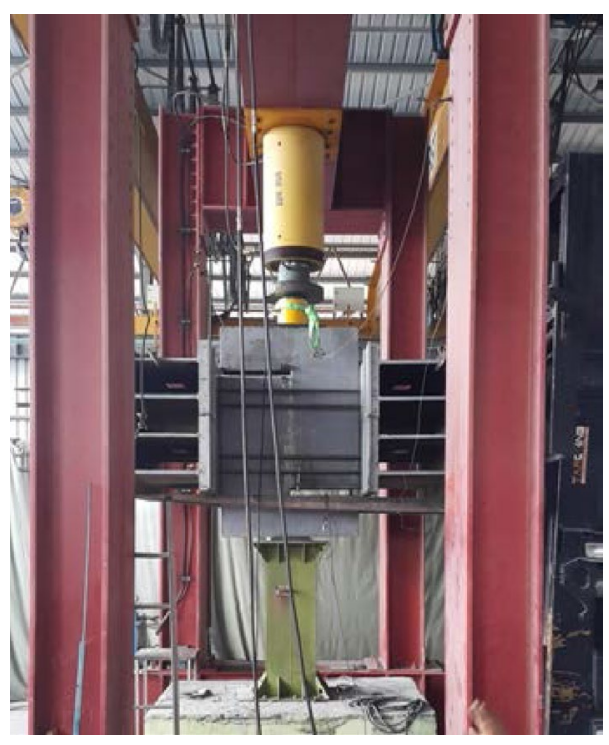

(c) Experimental setup

Fig. 2 Preparation and test setup of the experimental UHPFRC specimens DJ5-20 and EJ5-20

female components as well as the test control samples were sprayed with a curing compound.

Later, all UHPFRC specimens underwent heat treatment of $90{ }^{\circ} \mathrm{C}$ and $100 \%$ humidity for $48 \mathrm{~h}$ as recommended by the French Standard for UHPFRC (2016). The purpose of standard heat curing was to achieve densifying in the hardened state of UHPFRC, accelerate all long-term creep and shrinkage thus leading to a stable geometrical structure and improving the overall durability and strength of the composite material. For the epoxy joint specimen EJ520 , after applying the epoxy resin on the male component
(Fig. 2a), 5-ton concrete block were positioned on top to densely compress the male and female components together.

Confining pressures of $20 \mathrm{MPa}$ was applied to the dry and epoxy joints using 8 numbers of $15.2 \mathrm{~mm}$ diameter prestressing strands. In this experiment, two LVDTs were used to measure slip between male and female components of the UHPFRC joint specimens as presented in Fig. 2b. As shown in Fig. 2c, load cell and hydraulic jack with capacity of 500 $\mathrm{kN}(112,000 \mathrm{lb})$ were utilised to apply the direct shear load with a stroke rate of $0.005 \mathrm{~mm} / \mathrm{s}$ during test. 
Table 2 Test results on material properties of UHPFRC

\begin{tabular}{llcl}
\hline Mechanical properties & Units & Mean value & SD \\
\hline Modulus of elasticity $\left(E_{0}\right)$ & $\mathrm{GPa}$ & 45.8 & 0.85 \\
Cube compressive strength $\left(f_{\text {cm,cu }}\right)$ & $\mathrm{MPa}$ & 170.4 & 6.87 \\
Tensile limit of elasticity $\left(f_{\mathrm{ctm}, \mathrm{el}}\right)$ & $\mathrm{MPa}$ & 9.4 & 0.07 \\
Post-cracking tensile strength $\left(f_{\mathrm{ctfm}}\right)$ & $\mathrm{MPa}$ & 13.2 & 0.92 \\
Equivalent flexural strength $\left(f_{\mathrm{ctm}, \mathrm{fl}}\right)$ & $\mathrm{MPa}$ & 30.7 & 2.0 \\
\hline
\end{tabular}

The test results of the concrete mechanical properties according to the French Standard for UHPFRC (2016) is indicated in Table 2. A total of six $100 \times 100 \times 100 \mathrm{~mm}$ cubes an six $100 \times 100 \times 500 \mathrm{~mm}$ prisms were tested at 28 days to calculate mean cube compressive strength $\left(f_{\mathrm{cm}, \mathrm{cu}}\right)$, tensile limit of elasticity $\left(f_{\mathrm{ctm}, \mathrm{el}}\right)$ and post-cracking tensile strength $\left(f_{\mathrm{ctfm}}\right)$ of the UHPFRC. The characteristic yield strength $\left(f_{\mathrm{pk}}\right)$, elastic modulus $\left(E_{\mathrm{p}}\right)$, and Poisson's ratio $(v)$ of prestressing strands were taken as $1860 \mathrm{MPa}, 195 \mathrm{GPa}$ and 0.3 , respectively. Similar material properties was used during analyzing of the FE joint models.

As shown in Figs. 3a and 4a, it can be seen that the male key zones were detached from keyed joint specimens DJ520 and EJ5-20 once reaching the ultimate shear capacity $\left(V_{\mathrm{j}, \mathrm{u}, \operatorname{Exp}}\right)$.

From the experimental observations, the initial cracks at key zones of the joint specimens were initially occurredon the bottom of the male key zones at shear loads about $2300 \mathrm{kN}$ and $2700 \mathrm{kN}$ in DJ5-20 and EJ5-20, respectively due to the concentration of the shear stress. At this stage, the existence of steel fibres in the UHPFRC keyed joints improved the shear stress transmission which were almost perpendicular to the crack growth direction. This scenario proves the theories of inelastic behaviour and very high

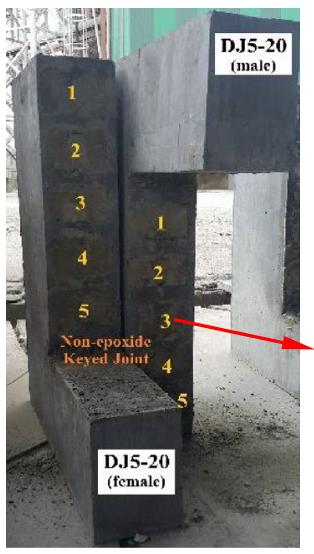

(a) Experimental failure

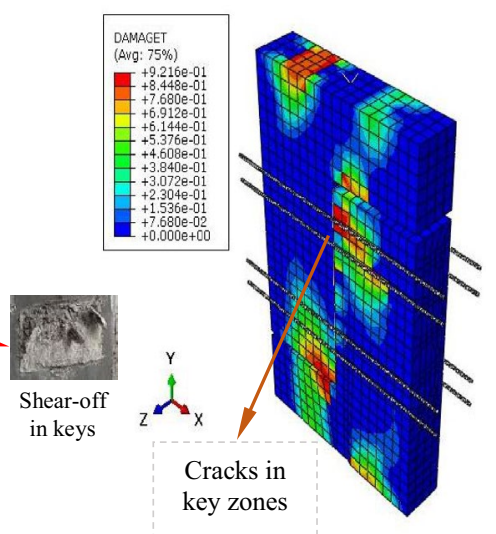

(b) Damage in tension

Fig. 3 Comparison of the experimental and FE results for DJ5-20

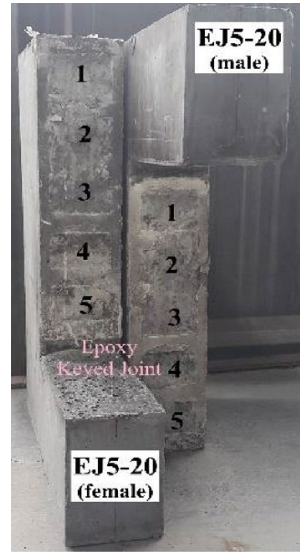

(a) Experimental failure

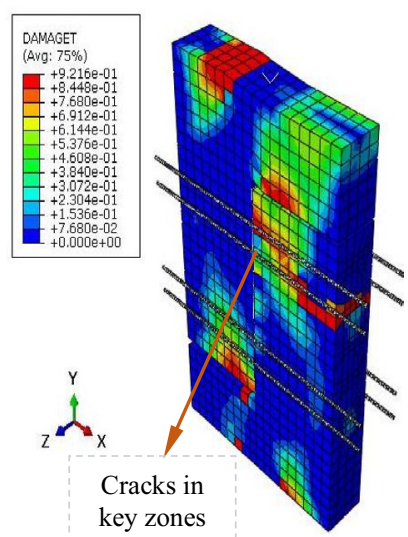

(b) Damage in tension

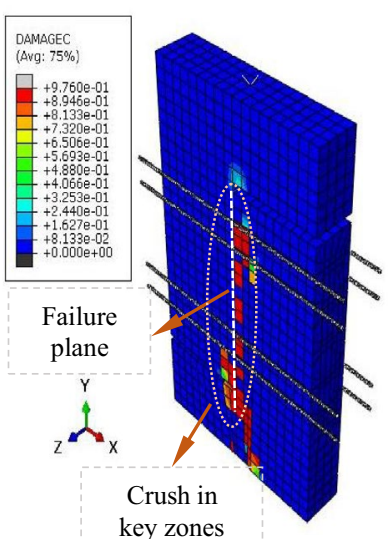

(c) Damage in compression

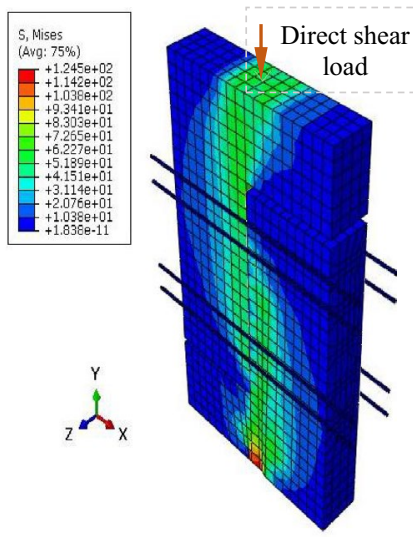

(d) Stress distribution

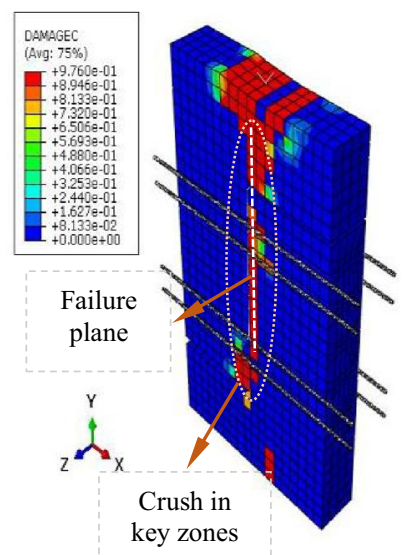

(c) Damage in compression

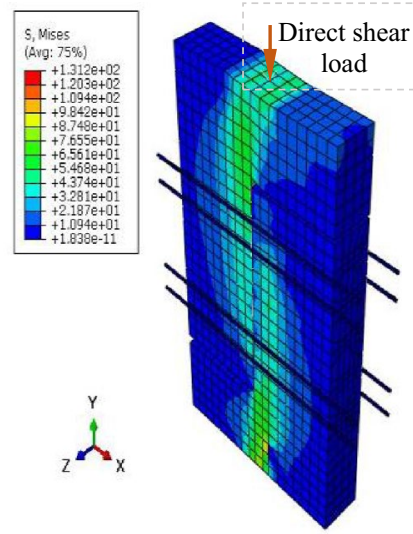

(d) Stress distribution

Fig. 4 Comparison of the experimental and FE results for EJ5-20 
ductility of UHPFRC which leads to an un-brittle failure mechanism. By increasing the direct shear load during the experimental tests, the ultimate shear capacity loads of 3216 $\mathrm{kN}$ and $3495 \mathrm{kN}$ were recorded for DJ5-20 and EJ5-20, respectively. Furthermore, as shown in Fig. 5, $2.71 \mathrm{~mm}$ and $2.60 \mathrm{~mm}$ slips were measured at the ultimate shear capacities between the male and female components ofDJ5-20 and EJ5-20, respectively. From these results, it can be seen that epoxy joint has improved the ultimate shear capacity by $8 \%$ and reduced the corresponding slip between male and female components by $4 \%$.From the shear load-displacement curves (Fig. 5a, b), after the ultimate shear load stage, a sudden slip of the middle part occurred which led the specimens to experience sudden drops of load (shear off stage). Once the specimens were completely sheared off, gradual ascending patterns were observed in the shear force-displacement curves, which are attributed by the friction between the two male and female UHPFRC surfaces.

Similarly, from the FE models DJ5-20 and EJ5-20, the results demonstrated that the maximum tension and compression damages occurred at the key zone area as shown in Figs. 3b, c and 4b, c. This would arises due to the concentration of stress distributed along the shear failure plane during applying direct shear load (see Figs. 3d, 4d). From Fig. 5, the FE graphs indicate a sign of reduction in linear elasticity after initial damages in tension and compression and then propagated in an upward direction until failure (shear-off) of the male and female components $\left(V_{\mathrm{j}, \mathrm{u}, \mathrm{FEM}}\right)$.It can be seen from the FE models (see Figs. 3c, 4c) that less compressive damage occurred on the UHPFRC joint models due to the high compressive strength of the UHPFRC $\left(f_{\mathrm{cm}, \mathrm{cu}}=170.4 \mathrm{MPa}\right)$. As shown in Figs. $3 \mathrm{~b}$ and $4 \mathrm{~b}$, more damage was observed due to the tension that occurred at the centre part of the key zone.

Following the shear-off stage, the specimens and FE models continued resisting the applied shear force through the existence of friction between contacted surfaces.

The shear load-displacement curves obtained from experimental and numerical results for specimens DJ5-20 and EJ5-20 are illustrated in Fig. 5a, b, respectively. A comparison between experimental results and numerical responses is carried out in Table 3. From this table, the ultimate shear loads $\left(V_{\mathrm{j}, \mathrm{u}, \mathrm{FEM}}\right)$ obtained numerically from both the joint models DJ5-20 and EJ5-20 match well with the ultimate shear loads $\left(V_{\mathrm{j}, \mathrm{u}, \mathrm{Exp}}\right)$ obtained from experimental study. A maximum difference of $0.8 \%$ is observed between FE and experimental results of the five-keyed dry joint (DJ5-20). Moreover, a maximum difference of $5.4 \%$ is observed in terms of slip between male and female components of the five-keyed epoxy joint (EJ5-20) at ultimate from the experimental and numerical results. Hence, the excellent agreement between simulation and experimental results demonstrates the reliability of the proposed numerical model for UHPFRC keyed dry or epoxy joints.

Figure $6 \mathrm{a}-\mathrm{c}$ shows the numerical shear load-displacement curves of the single-keyed, three-keyed and five-keyed

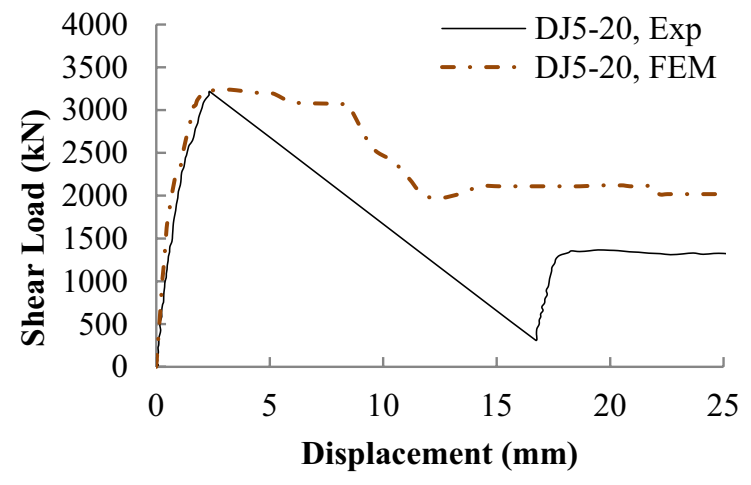

(a) Five-keyed dry joint

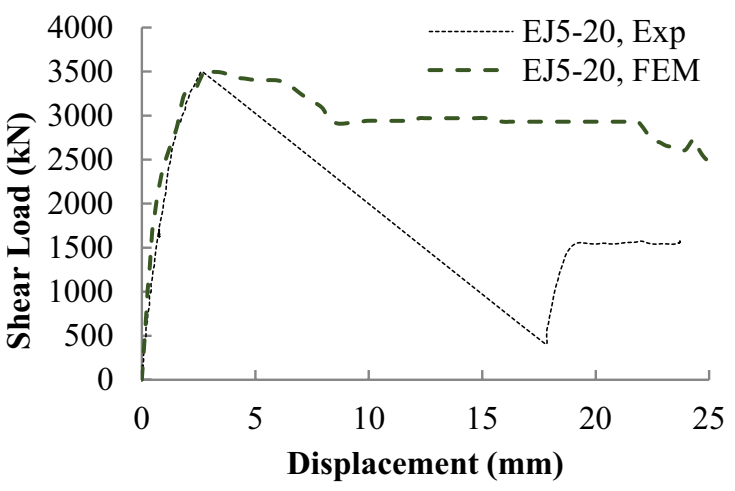

(b) Five-keyed epoxy joint

Fig. 5 Shear load-displacement curves from experimental and FE results for DJ5-20 and EJ5-20

Table 3 Comparison of experimental and numerical results

\begin{tabular}{lllllll}
\hline Specimen & $V_{\mathrm{j}, \mathrm{u}, \mathrm{Exp}}(\mathrm{kN})$ & $V_{\mathrm{j}, \mathrm{u}, \mathrm{FEM}}(\mathrm{kN})$ & $\begin{array}{l}\text { Percentage } \\
\text { difference } \\
(\%)\end{array}$ & $\operatorname{Dis}_{\mathrm{j}, \mathrm{u}, \operatorname{Exp}}(\mathrm{mm})$ & Dis $_{\mathrm{j}, \mathrm{u}, \mathrm{FEM}}(\mathrm{mm})$ & $\begin{array}{l}\text { Percentage } \\
\text { difference } \\
(\%)\end{array}$ \\
\hline DJ5-20 & 3216 & 3241 & 0.8 & 2.71 & 2.74 & 1.1 \\
EJ5-20 & 3495 & 3521 & 0.7 & 2.60 & 2.74 & 5.4 \\
\hline
\end{tabular}




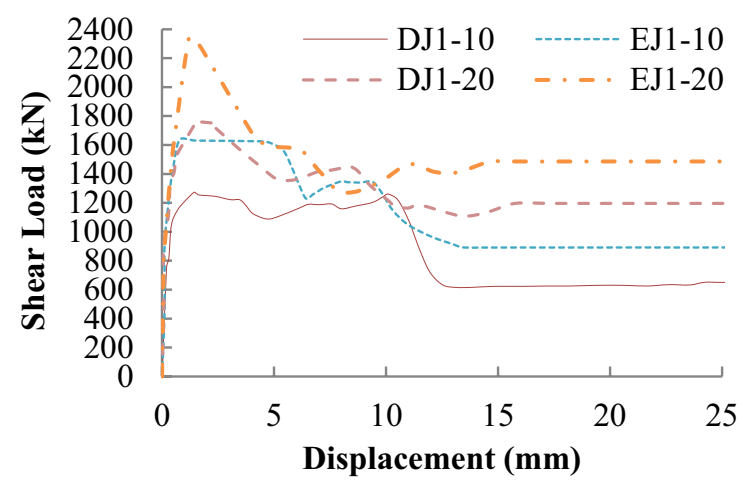

(a) Single-keyed joint models

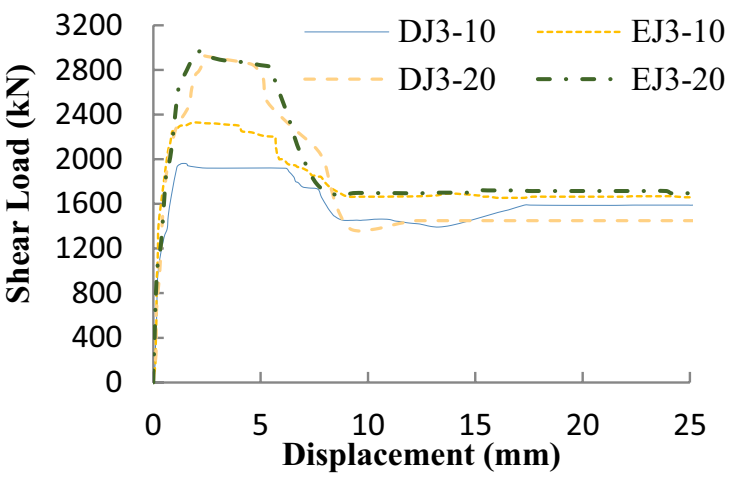

(b) Three-keyed joint models

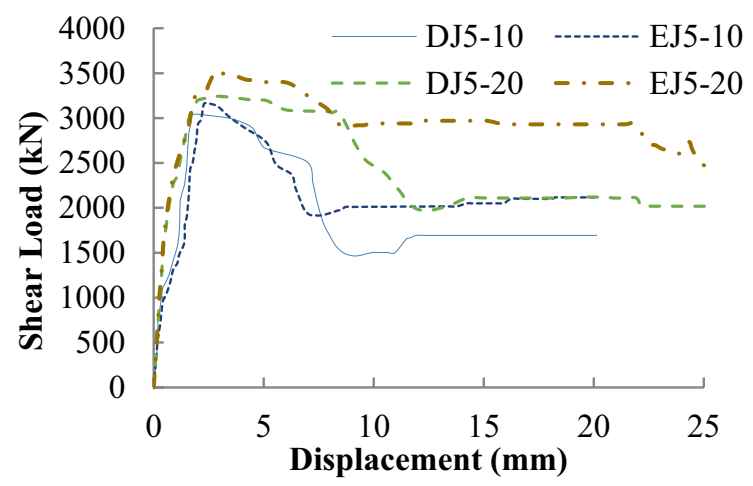

(c) Five-keyed joint models

Fig. 6 Numerical shear load-displacement curves for UHPFRC keyed joint models

joint models, respectively under direct shear load considering two variables, types of joint (dry or epoxy) and amount of confining pressure (10 $\mathrm{MPa}$ and $20 \mathrm{MPa})$. As expected and presented in Table 4, it can be seen that the ultimate shear loads $\left(V_{\mathrm{j}, \mathrm{u}, \mathrm{FEM}}\right)$ are higher at the keyed epoxy joint models with larger confining pressure. As shown in Fig. 6a-c, the ultimate shear capacities of EJ1-20, EJ3-20 and EJ5-20 improved by 45.6\%, 34\%, and $13.5 \%$, respectively compared to DJ1-10, DJ3-10 and DJ5-10. Hence, by increasing the number of shear keys, the effects of epoxy and confining pressure on the ultimate shear load will decrease.

The ultimate shear load $\left(V_{\mathrm{j}, \mathrm{u}, \mathrm{FEM}}\right)$ and the corresponding displacement $\left(\right.$ Dis $_{\mathrm{j}, \mathrm{u}, \mathrm{FEM}}$ ) from analysis of the five-keyed dry joint model DJ5-10 are $3045 \mathrm{kN}$ and $1.87 \mathrm{~mm}$, respectively as presented in Fig. 6c. While, the ultimate shear load and the corresponding displacement from analysis of the fivekeyed epoxy joint model EJ5-20 are $3521 \mathrm{kN}$ and $2.74 \mathrm{~mm}$, respectively. In overall, by considering all parameters (i.e. number of shear keys, confining stress, and types of joints), the ultimate shear capacity of EJ5-20 improved remarkably by $64 \%$ compared to DJ1-10 as shown in Table 4 . Also, at ultimate shear capacity, slip between male and female
Table 4 Results of parametric study on various keyed joint models

\begin{tabular}{lll}
\hline Models & $V_{\mathrm{j}, \mathrm{u}, \mathrm{FEM}}(\mathrm{kN})$ & Dis $_{\mathrm{j}, \mathrm{u}, \mathrm{FEM}}(\mathrm{mm})$ \\
\hline DJ1-10 & 1270 & 1.42 \\
EJ1-10 & 1636 & 0.78 \\
DJ1-20 & 1772 & 1.58 \\
EJ1-20 & 2335 & 1.19 \\
DJ3-10 & 1962 & 1.45 \\
EJ3-10 & 2330 & 1.71 \\
DJ3-20 & 2925 & 2.39 \\
EJ3-20 & 2972 & 2.54 \\
DJ5-10 & 3045 & 1.87 \\
EJ5-10 & 3167 & 2.35 \\
DJ5-20 & 3241 & 2.74 \\
EJ5-20 & 3521 & 2.74 \\
\hline
\end{tabular}

components(Dis $\left.{ }_{\mathrm{j}, \mathrm{u}, \mathrm{FEM}}\right)$ of EJ5-20 increased up to $99 \%$ compared with DJ1-10, which indicates a higher energy dissipation capacity (area below shear load-displacement curve) of the keyed epoxy joint models with more shear keys and larger confining pressure before shearing-off failure. 


\section{Comparison of existing provisions with experimental and FEM results for keyed dry joint models}

The application of the existing formulations proposed by the various authors leads to significantly different values for the ultimate shear capacity $\left(V_{\mathrm{j}, \mathrm{u}, \text { Exist }}\right)$ of the dry keyed joint as presented in Table 5. Besides, based on an extensive review of the literature, there is no design provision model available to estimate the ultimate shear capacity of the UHPFRC epoxy keyed joints. In this paper, a brief overview of the existing shear joint strength found in the literature was already explained. Some of these formulas have a theoretical basis while others are empirically derived from experimental studies. As illustrated in Table 5, all five existing joint design provision models as given in Eqs. (1)-(6) were used to compare against the experimental results of the full-scale UHPFRC five-keyed dry joint DJ5-20 since all these design provisions are formulated based on dry keyed joints. From this table, minimum and maximum differences of $13 \%$ and $87 \%$ were observed between results of Kaneko et al. (1993) and ASSHTO (1999) provision models with experimental data in terms of ultimate shear load capacities, respectively.

Furthermore, the five existing joint design provision models were used to compare against the numerical dry shear keyed joint results since all these design provisions are formulated based on dry shear keyed joints. The mean Exist/FEM ratios, standard deviation (SD) and coefficient of variations (COV) of the all the keyed dry joint models used in this study are presented in Table 6. From this table, results obtained from design provisions by Kaneko et al. (1993) and Turmo et al. (2006) are close to the results that obtained from the proposed numerical model in this research. Mean Exist/FEM ratios of 1.01 and 1.09 exhibit good correlation between results from these two design provisions with the proposed FEM results. However, AASTHO (1999) provision is not providing a reasonable correlation with FEM data which led to the worst mean Exist/FEM ratio of 1.46 and the highest inconsistency of results with a COV of $17.6 \%$. A maximum difference of $87 \%$ is observed between results of ASSHTO and FEM for five-keyed dry joint model (DJ5-20)under confining pressure of $20 \mathrm{kN}$.

As shown in Fig. 7, the safe zone comparison graph clearly shows that the majority of the ultimate shear capacities calculated through the existing design provisions (AASHTO 1999; ATEP 1996; Rombach and Specker 2004) are in the unsafe zone which leads to an unsafe correlation with the numerical results of the UHPFRC keyed dry joints. However, the ultimate shear capacities calculated using design provisions Kaneko et al. (1993) and Turmo et al. (2006) are mostly located in the safe zone and provide good correlation with FEM results. However, this comparison study indicated that new design provision models should be developed to estimate the shear capacity of UHPFRC dry and epoxy joints.

Table 5 Comparison of existing provision models withexperimental data for DJ5-20

\begin{tabular}{|c|c|c|c|c|c|c|c|c|c|c|c|}
\hline \multirow[t]{2}{*}{ Models } & \multirow{2}{*}{$\begin{array}{l}\text { Exp. } \\
V_{\mathrm{j}, \mathrm{u}, \operatorname{Exp}}(\mathrm{kN})\end{array}$} & \multicolumn{2}{|c|}{ Kaneko et al. (1993) } & \multicolumn{2}{|l|}{ ATEP (1996) } & \multicolumn{2}{|c|}{ AASHTO (1999) } & \multicolumn{2}{|c|}{$\begin{array}{l}\text { Rombach and Specker } \\
\text { (2004) }\end{array}$} & \multicolumn{2}{|c|}{ Turmo et al. (2006) } \\
\hline & & $V_{\mathrm{j}, \mathrm{u}, \text { Exist }}(\mathrm{kN})$ & $\frac{\text { Exist }}{\text { Exp }}$ & $V_{\mathrm{j}, \mathrm{u}, \text { Exist }}(\mathrm{kN})$ & $\frac{\text { Exist }}{\text { Exp }}$ & $V_{\mathrm{j}, \mathrm{u}, \text { Exist }}(\mathrm{kN})$ & $\frac{\text { Exist }}{\operatorname{Exp}}$ & $V_{\mathrm{j}, \mathrm{u}, \text { Exist }}(\mathrm{kN})$ & $\frac{\text { Exist }}{\text { Exp }}$ & $V_{\mathrm{j}, \mathrm{u}, \text { Exist }}(\mathrm{kN})$ & $\frac{\text { Exist }}{\text { Exp }}$ \\
\hline DJ5-20 & 3216 & 3649 & 1.13 & 4490 & 1.40 & 5999 & 1.87 & 3708 & 1.15 & 4458 & 1.39 \\
\hline
\end{tabular}

Table 6 Comparison of existing provisions with the proposed FEM results

\begin{tabular}{|c|c|c|c|c|c|c|c|c|c|c|c|}
\hline \multirow[t]{2}{*}{ Models } & \multirow{2}{*}{$\begin{array}{l}\text { FEM } \\
V_{\mathrm{j}, \mathrm{u}, \mathrm{FEM}}(\mathrm{kN})\end{array}$} & \multicolumn{2}{|c|}{ Kaneko et al. (1993) } & \multicolumn{2}{|l|}{ ATEP (1996) } & \multicolumn{2}{|c|}{ AASHTO (1999) } & \multicolumn{2}{|c|}{$\begin{array}{l}\text { Rombach and Specker } \\
\text { (2004) }\end{array}$} & \multicolumn{2}{|c|}{ Turmo et al. (2006) } \\
\hline & & $V_{\mathrm{j}, \mathrm{u}, \text { Exist }}(\mathrm{kN})$ & $\frac{\text { Exist }}{\mathrm{FEM}}$ & $V_{\mathrm{j}, \mathrm{u}, \text { Exist }}(\mathrm{kN})$ & $\frac{\text { Exist }}{\text { FEM }}$ & $V_{\mathrm{j}, \mathrm{u}, \text { Exist }}(\mathrm{kN})$ & $\frac{\text { Exist }}{\text { FEM }}$ & $V_{\mathrm{j}, \mathrm{u}, \text { Exist }}(\mathrm{kN})$ & $\frac{\text { Exist }}{\text { FEM }}$ & $V_{\mathrm{j}, \mathrm{u}, \text { Exist }}(\mathrm{kN})$ & $\frac{\text { Exist }}{\text { FEM }}$ \\
\hline DJ1-10 & 1270 & 1183 & 0.93 & 1393 & 1.09 & 1465 & 1.15 & 1366 & 1.07 & 1094 & 0.86 \\
\hline DJ1-20 & 1772 & 2266 & 1.24 & 2434 & 1.33 & 2736 & 1.50 & 2406 & 1.32 & 2044 & 1.12 \\
\hline DJ3-10 & 1962 & 1630 & 0.83 & 2259 & 1.16 & 2476 & 1.27 & 2017 & 1.03 & 1842 & 0.94 \\
\hline DJ3-20 & 2925 & 2958 & 1.09 & 3462 & 1.28 & 4368 & 1.61 & 3057 & 1.13 & 3251 & 1.20 \\
\hline DJ5-10 & 3045 & 2077 & 0.83 & 3125 & 1.24 & 3487 & 1.39 & 2668 & 1.06 & 2590 & 1.03 \\
\hline DJ5-20 & 3241 & 3649 & 1.13 & 4490 & 1.40 & 5999 & 1.87 & 3708 & 1.15 & 4458 & 1.39 \\
\hline Mean & & & 1.01 & & 1.25 & & 1.46 & & 1.13 & & 1.09 \\
\hline SD & & & 0.17 & & 0.11 & & 0.26 & & 0.10 & & 0.19 \\
\hline $\mathrm{COV}$ & & & 17.0 & & 9.0 & & 17.6 & & 9.2 & & 17.5 \\
\hline
\end{tabular}


Fig. 7 Safe zone comparison of the existing provisions to the FEM results

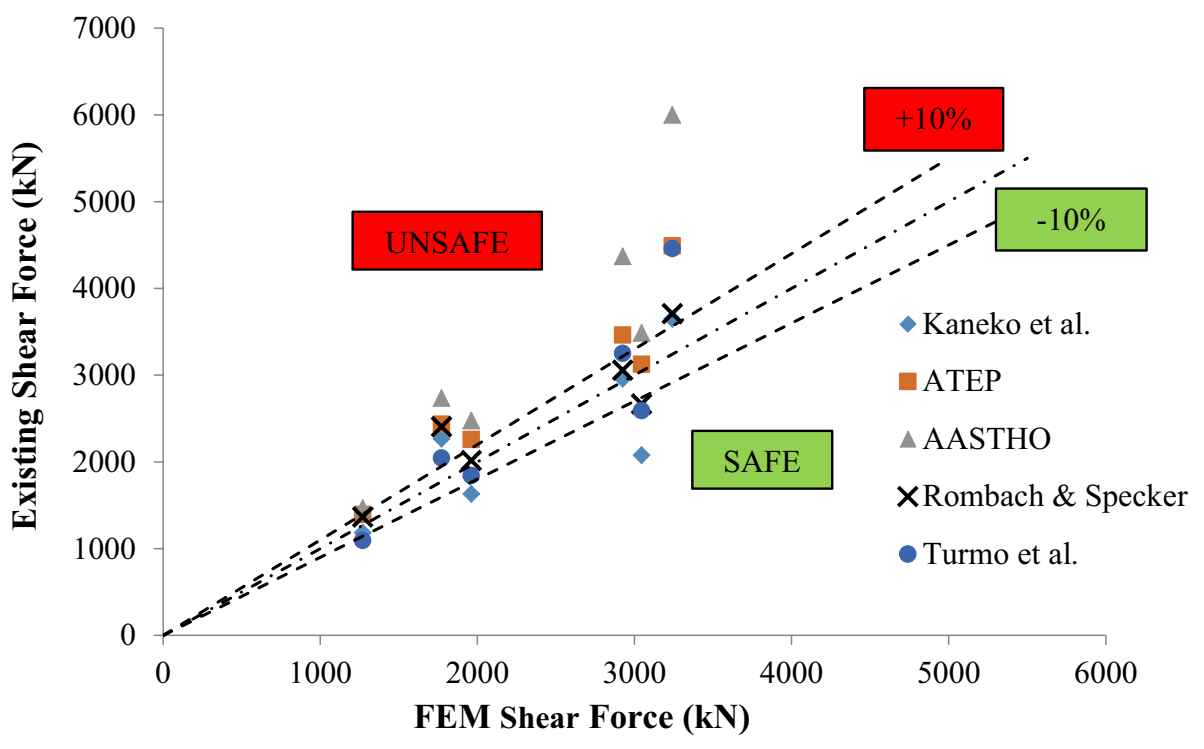

\section{Conclusion}

In order to accurately investigate the shear behavior of the joints in UHPFRC precast segmental bridges, a numerical analysis model based on finite-element (FE) code was established in this study. To validate the proposed numerical model, two full-scale UHPFRC five-keyed dry and epoxy joints were fabricated and tested experimentally under direct shear load. Maximum differences of $0.8 \%$ and $5.4 \%$ were observed between the ultimate shear loads and corresponding slips, respectively from comparison of FE and experimental observations. The excellent agreement between the numerical results and experimental data demonstrated the reliability of the present model. Moreover, a parametric study was carried out to evaluate the effects of the number of shear keys, confining stress, and types of joints on the shear capacity of the UHPFRC keyed joint models. Results from the developed numerical models showed that the capacity of the UHPFRC key joints increased with increasing horizontal pressure applied across the joint (confining stress), number of shear keys and the epoxy layers applied on joints. Considering all the parameters, the ultimate shear capacity improved remarkably up to $64 \%$. However, by increasing the number of shear keys, the effects of epoxy and confining pressure on the ultimate shear load was reduced. Finally, the FE data and experimental results were compared with the results from five existing shear design provisions available in literature for RC keyed dry joints.Findings indicated that existing shear design models lead to unsafe and inconsistent results on UHPFRC dry keyed joints. All the five provisions tend to over-estimate the $V_{\mathrm{j}, \mathrm{u}}$ under higher confining stress. AASHTO (1999) design provision led to the worst mean Exist/FEM of 1.46 and COV of $17.6 \%$. The simulations outlined in this study were limited to the response of the UHPFRC shear joints and nonlinear analysis of complete UHPFRC precast segmental bridges is recommended for the future studies. Moreover, it is recommended to develop a new constitutive model for UHPFRC considering the effect of steel fiber orientation in future FE studies of shear keyed joints.

Acknowledgements This research receives financial and technical support from Dura Technology Sdn. Bhd. Their help and support are gratefully acknowledged.

Open Access This article is distributed under the terms of the Creative Commons Attribution 4.0 International License (http://creativeco mmons.org/licenses/by/4.0/), which permits unrestricted use, distribution, and reproduction in any medium, provided you give appropriate credit to the original author(s) and the source, provide a link to the Creative Commons license, and indicate if changes were made.

\section{References}

AASHTO, American Association of State Highway and Transportation Officials (1999) Guide specifications for the design and construction of segmental concrete bridges, Second Edition. Washington, DC

ATEP, Spanish Standdard (1996) Project and construction of bridges and structures with external prestressing. Madrid (In Spanish)

Binard JP (2017) UHPC: A game-changing material for PCI bridge producers. PCI J 62(2):34-46

BS EN 1992-1-1, European Committee for Standardization (CEN) (2004) Eurocode 2: Design of concrete structures. Part 1-1: General rules and rules for buildings

$\mathrm{Bu} \mathrm{ZY}, \mathrm{Wu}$ WY (2018) Inter shear transfer of unbonded prestressing precast segmental bridge column dry joints. Eng Struct 154:5265. https://doi.org/10.1016/j.engstruct.2017.10.048

Buttignol TET, Sousa JLAO, Bittencourt TN (2017) Ultra high-performance fiber-reinforced concrete (UHPFRC): a review of material properties and design procedures. Rev IBRACON Estruturas e 
Mater 10:957-971. https://doi.org/10.1590/s1983-4195201700 0400011

Chen B, An M, Huang Q, Wu H, Zhao Q (2016) Application of ultrahigh performance concrete in bridge engineering in China. In: First International Interactive Symposium on UHPC. pp 1-8

El-Tawil S, Tai Y, Belcher JA (2018) Field application of nonproprietary ultra-high-performance concrete. Concr Int 40:36-42

Hafezolghorani M, Voo YL (2018) Design of 38 m Span Post-tensioned Ultra High Performance Fiber-Reinforced Concrete (UHPFRC) Composite Bridge. IOP Conf Ser Mater Sci Eng 14th Int Conf Concr Eng Technol 431:1-10. https://doi.org/10.1088/1757899x/431/4/042007

Hafezolghorani M, Hejazi F, Vaghei R, Bin Jaafar MS, Karimzade K (2017) Simplified damage plasticity model for concrete. Struct Eng Int 27:68-78. https://doi.org/10.2749/101686616X1081

Han Q, Zhou Y, Ou Y, Du X (2017) Seismic behavior of reinforced concrete sacrificial exterior shear keys of highway bridges. Eng Struct 139:59-70. https://doi.org/10.1016/j.engstruct.2017.02.034

Hu ZN, Xie YL (2016) Mechanical and Failure characteristics of shear keys on immersed tunnel segment joints under differential settlements. Procedia Eng 166:373-378. https://doi.org/10.1016/j. proeng.2016.11.564

Issa MA, Abdalla HA (2007) Structural behavior of single key joints in precast concrete segmental bridges. J Bridg Eng 12:315-324

Jang HO, Lee HS, Cho K, Kim J (2017) Experimental study on shear performance of plain construction joints integrated with ultra-high performance concrete (UHPC). Constr Build Mater 152:16-23. https://doi.org/10.1016/j.conbuildmat.2017.06.156

Kaneko Y, Connor JJ, Triantafillou TC, Leung CK (1993) Fracture mechanics approach for failure of concrete shear key. I: theory. J Eng Mech 119:681-700

Mansur MA, Ong KCG (1991) Behavior of reinforced fiber concrete deep beams in shear. Struct J 88:98-105

Mihu G, Mihalache I, Graur I, Ungureanu C, Bria V (2017) Comparative study regarding friction coefficient for three epoxy resins. In: IOP Conference Series: Materials Science and Engineering, vol 174, issue 1. IOP Publishing, pp 012024

NF P 18-470: 2016-07, French Standard, (2016) Concrete-ultra-high performance fiber-reinforced concrete-specifications, performance, production and conformity, AFNOR

Rombach G (2004) Dry joint behavior of hollow box girder segmental bridges. In: FIP Symposium "Segmental Construction in Concrete." New Delhi
Rombach GA, Specker A (2004) Segmentbrücken. Beton-Kalender, Teil 1. Ernst und Sohn, Berlin, pp 177-211

Shamass R, Zhou X, Alfano G (2015) Finite-element analysis of shear-off failure of keyed dry joints in precast concrete segmental bridges. J Bridg Eng 20:04014084. https://doi.org/10.1061/ (ASCE)BE.1943-5592.0000669

Shamass R, Zhou X, Wu Z (2016) Numerical analysis of shear-off failure of keyed epoxied joints in precast concrete segmental bridges. J Bridg Eng 22:4016108

Shin J (2017) Ultra-High Performance Concrete (UHPC) Precast segmental bridges: flexural behaviour and joint design. Shaker (Thesis)

Turmo J, Ramos G, Aparicio AC (2006) Shear strength of dry joints of concrete panels with and without steel fibres: application to precast segmental bridges. Eng Struct 28:23-33

Version, A. B. A. Q. U. S. 6.11, 2011. Analysis User's Manual. Dassault Systemes Simulia Corp., Providence, RI, 25.

Voo YL, Foster J (2016) Design and Construction of the 100 metre Span UHPC Batu 6 Segmental Box Girder Bridge. In: HiPerMat 2016 4th International Symposium on Ultra-High Performance Concrete and High Performance Materials Kassel, pp 1-8

Voo YL, Foster SJ, Voo CC (2014) Ultrahigh-performance concrete segmental bridge technology: toward sustainable bridge construction. J Bridg Eng 20:B5014001. https://doi.org/10.1061/(ASCE) BE.1943-5592.0000704

Voo YL, Hafezolghorani M, Foster S (2018) Application of ultra-highperformance-fiber reinforced concrete technology for present and future. In: Proceedings of UHPC2018-China, The 2nd International Conference on UHPC Materials and Structures. November 4-7, 2018, Fuzhou, China

Zhou X, Mickleborough N, Li Z (2005) Shear strength of joints in precast concrete segmental bridges. ACI Struct J 102:3

Publisher's Note Springer Nature remains neutral with regard to jurisdictional claims in published maps and institutional affiliations. 